일반논문-11-16-3-07

$$
\begin{aligned}
& \text { 실시간 방치 및 제거 객체 검출 시스템 } \\
& \text { 정 철 준 }{ }^{\mathrm{a}} \text {, 안 태 기 }{ }^{\mathrm{b})} \text {, 박 종 화 }{ }^{\mathrm{a})} \text {, 박 구 만 }{ }^{\mathrm{f}}
\end{aligned}
$$

\title{
Real Time Abandoned and Removed Objects Detection System
}

\author{
Cheol-Jun Jeong ${ }^{\text {a) }}$, Tae-Ki Ahn ${ }^{\text {b) }}$, Jong-Hwa Park ${ }^{\text {a) }}$, and Goo-Man Park ${ }^{\text {() }}$ \\ 요 약
}

본 논문에서는 실시간 영상감시 시스템에서 방치되거나 제거된 객체를 강인하게 검출하는 알고리듬을 제안한다. 방치되거나 없어진 객 체는 사람이나 다른 움직임의 원인에 의해서 나타나기 때문에 추적을 기반으로 한 방법을 사용하였다. 가우시안 혼합 모델에 의해 전경과 배경을 분리하고 그림자 제거 알고리듬을 적용하였다. 모폴로지를 수행하여 주변 잡음을 제거하고 객체 구분을 명확히 하였다. 그리고 검 출된 정지 객체를 방치되거나 사라지는 객체 중의 하나로 분류하였다. 추적방법을 적용함과 동시에 정지된 객체에 모니터링 시간까지 부 여하여 검출된 객체가 다른 객체에 의해서 폐색되는 현상을 개선하였다. 영역성장기법을 이용하여 방치된 객체와 제거된 객체의 분류 성 능을 높였다. 또한 제안된 시스템을 DSP 기반으로 설계하여 실시간 구현을 하였다. 실험을 통해 제안한 방법의 우수성을 입증하였다.

\section{Abstract}

We proposed a realtime object tracking system that detects the abandoned or disappeared objects. Because these events are caused by human, we used the tracking based algorithm. After the background subtraction by Gaussian mixture model, the shadow removal is applied for accurate object detection. The static object is classified as either of abandoned objects or disappeared object. We assigned monitoring time to the static object to overcome a situation that it is being overlapped by other object. We obtained more accurate detection by using region growing method. We implemented our algorithm by DSP processor and obtained an excellent result throughout the experiment.

Keyword : Intelligent Surveillance System, Abandoned Object, Removed Object, Object Detection

\section{I. 서 론}

컴퓨터 비전 기술을 이용하여 움직이는 객체를 검출하고

a) 하이트론 씨스템즈(주)

Hitron Systems.Co..Ltd.

b) 한국철도기술연구원

Korea Railroad Research Institute

c) 서울과학기술대학교 매체공학과

Seoul National University of Science and Technology, Dept.of.Media Engineering

\# 교신저자 : 박구만(gmpark@seoultech.ac.kr)

※ 본 연구는 국토해양부 도시철도표준화 2단계 연구개발사업의 연구비지원 (07도시철도표준화A01)에 의해 수행되었습니다.

· 접수일(2011년3월3일),수정일(2011년5월6일),게재확정일(2011년5월20일)
실시간으로 추적하는 기술은 무인 감시 시스템, 지능형 교 통 시스템 등 다양한 분야에서 응용이 가능하다. 객체 검출 및 추적 시스템은 입력되는 영상을 분석하여 움직이는 객 체를 검출하고, 필요에 따라 그 검출된 객체의 움직인 궤적 에 따라서 카메라가 자동으로 동작하도록 구성하는 시스템 을 말한다. 최근 세계적으로 테러나 전쟁과 같은 범죄나 위 험 상황이 빈번하게 발생함에 따라 각국은 보안에 대한 중 요성을 크게 인식하게 되었다. 또한, 이에 대한 대비책 마련 을 위한 관련 기술도 크게 발전하고 있다. 최근에는 공공장 소에서의 주요 시설물의 도난과 같은 범죄에서부터 폭발물 
을 비롯한 위험물 투기 및 방치 등의 다양한 범죄들이 발생 하고 있다. 이러한 이유로 인해 유동인구가 많은 공항, 버스 정류장, 지하철역과 같은 공공 교통 시설 구역에서의 보행 자 안전 문제가 크게 대두되고 있다. 각 지역에서 일어날 수 있는 테러에 대비하기 위해 많은 나라들이 보안 분야에 지속적으로 연구와 투자를 진행하고 있다.

보안 감시 시스템의 활용이 늘어나고 있지만, 인력만으 로 감시하는 데는 한계가 있다. 많은 모니터를 감시하다 보 면 중요한 장면을 놓치거나 잘못 판단하는 경우가 발생할 수 있다. 이러한 경우 큰 피해가 발생할 수 있다. 따라서 객체추적기술에 의해 자동화된 지능형 종합감시시스템에 대한 개발이 필요하다.

방치 및 제거된 객체 검출 알고리듬에 대한 연구는 지 난 수년간 지속적으로 진행되어 왔다. 대부분의 연구는 크게 객체 탐지 알고리듬을 기반으로 하는 방법과 객체 추적 알고리듬을 기반으로 하는 두 가지 방법으로 분류 할 수 있다. 첫 번째는 전경과 배경을 분리하는 데 있어서 차영상과 가우시안 혼합 모델(GMM,Gaussian Mixture Model)을 이용하는 것이다. 차영상은 이전 프레임과 현 재프레임의 영상의 차를 이용하여 전경과 배경을 분리하 는 방법이고, $\mathrm{GMM}$ 은 영상의 각 픽셀을 여러 개의 가우 시안으로 모델링하고 학습하는 방법이다. Sadiye $\mathrm{e}^{[1]}$ 는 차 영상을 이용하여 복잡한 환경에서의 움직이는 객체와 정 적인 객체를 구분하여 이전 영상과 차이를 구하여 방치 된 객체를 검출하는 알고리듬 구성하였다. 차영상은 빠 른 계산량과 쉬운 구현이 가능한 장점을 갖고 있지만 객 체 상태가 정적일 경우 판단의 모호함을 가진다. $\mathrm{GMM}$ 을 이용한 것으로는 $\mathrm{Lin}^{[2]}$ 이 제안한 방법이 있다. $\mathrm{GMM}$ 파 라미터 변경을 통하여 빠른 검출을 하는 모드-I의 GMM 과 정확한 검출을 위한 모드- П의 $\mathrm{GMM}$ 을 혼합하여 빠르 고 정확한 검출 알고리듬을 구현하고자 하였다. $\mathrm{GMM}$ 에 저역필터를 이용한 방법은 차영상과는 달리 정적인 영역 의 구분이 명확하고, 환경적 잡음에 강건한 특성을 가진 다. 두 번째는 객체 검출 후 추적 방법의 적용 여부에 따 라 객체를 판별하는 방법이다. Tian ${ }^{[3]}$ 이 제안한 알고리듬 에서는 추적 방법을 적용하여 움직임 및 정적인 영역을 검출하여 판별하도록 제안하였다. Vanetianer ${ }^{[4]}$ 도 추적
방법을 이용하여 객체 판별 및 분류 방법에 대해 제안하 였다. Miguel ${ }^{[5]}$ 역시 배경 업데이트 및 추적 방법을 이용 한 알고리듬을 제안하였다. 추적을 이용한 방법은 복잡 한 환경에서 향상된 특성을 가지고 있지만 계산량의 문 제와 폐색 발생 시 정확한 판별이 어려운 문제를 가진다. 단일 차영상을 사용할 것인지 다중 차영상을 사용할 것 인지에 따라 기존 논문을 분류할 수 있다. 두 부류 모두 프레임 대 프레임 해석과 부 샘플링된 해석으로 나눌 수 있다. Liao가 제안한 단일 차영상에서 부 샘플링 평활화 는 전체 프레임을 다 사용하지 않고 마스크 영상만을 이 용하여 'AND' 연산하여 남는 방치된 객체만을 검출하는 원리이다 ${ }^{[6]}$. Porikli의 다중 차영상 처리 방법에서도 마찬 가지로 움직임의 여부에 따라 동적 객체, 후보 객체, 모호 한 객체 또는 정적 객체 검출이 이루어지는 방법을 사용 한다 ${ }^{[7]}$.

제안된 시스템은 두 번째 방법인 추적방법을 적용함과 동시에 정지된 객체에 모니터링 시간까지 부여하여 검출된 객체가 다른 객체에 의해서 폐색되는 현상을 개선하고자 하였다. 또한 제안된 시스템을 DSP 기반으로 설계하여 다 른 방법으로 객체 검출을 할 때 보다 적응적이며 정확도가 높은 장점을 가진다. 또한 저가의 구성이 가능하고 수정이 간편하다.

본 논문의 구성은 다음과 같다. 2장에서는 본 논문에서 검출 방법으로 사용한 가우시안 혼합 모델에 대해서 소개 하였다. 3 장에서는 제안된 알고리듬인 방치되거나 제거된 객체 검출 알고리듬 구현 방법에 대해 설명하였다. 4장에서 는 제안된 알고리듬에 대한 실험 및 결과 고찰을 하였다. 끝으로 5 장에서는 본 논문에 대한 결론을 나타내고 필요한 추가 연구 방향 및 목표에 대해 언급하였다.

\section{II. 객체 검출을 위한 가우시안 혼합 모델}

가우시안 혼합 모델은 가우시안 커널(kernel)을 다수 혼 합하여 입력 영상 내 각 화소별로 커널을 적용해서 밀도가 높아지는 정도를 이용하여 배경과 객체를 분리 및 검출해 내는 방법이다. 이러한 가우시안 혼합 모델은 확률 분포를 
사용하는 영상 처리 분야에서 유용하게 사용되는 방법으로 서 다양한 환경적인 변화를 가지는 입력영상을 처리할 때 효과적이다.

가우시안 혼합 모델에서의 화소별 평균과 분산은 매 프 레임 별 학습이 이루어진다. 따라서 시간에 따라 화소 값이 변화해 학습에 따라 환경적으로 적응하는 구조를 가진다 ${ }^{[8][9]}$. 임의의 시간 $t$ 에 대해 측정한 한 화소가 $\vec{X}$ 라고 하고, 이 $\vec{X}$ 가 $M$ 개의 가우시안 확률 분포를 따른다고 하면, 가우 시안 혼합 모델은 식 (1)과 같다.

$$
p(\vec{X}, \vec{\theta})=\sum_{m=1}^{M} \pi_{m} N\left(\overrightarrow{X^{\prime}}, \overrightarrow{\mu_{m}}, C_{m}\right) \text { with } \sum_{m=1}^{M} \pi_{m}=1
$$

여기서 $\vec{\theta}$ 는 가우시안 혼합 모델의 파라미터 벡터로 $\vec{\theta}=\pi_{1}, \cdots, \pi_{m}, \overrightarrow{\mu_{1}}, \cdots, \overrightarrow{\mu_{m}}, C_{1}, \cdots, C_{m}$ 이며, $\overrightarrow{\mu_{m}}$ 과 $C_{m}$ 은 $\mathrm{m}$ 번 째 가우시안 분포의 평균과 공분산 행렬이다. 또한 $\pi_{m}$ 은 $\mathrm{m}$ 번째 가우시안 분포의 혼합 가중치를 나타낸다. $t$ 의 다음 시간인 $t+1$ 에 대해 새로운 화소 값 $\vec{X}^{(t+1)}$ 이 주어지면 가 우시안 파라미터 모델은 적응적으로 새롭게 학습된다. 새 롭게 학습된 $t+1$ 에서의 모델링은 아래의 식 (2), (3), (4)와 같다.

$$
\begin{gathered}
\overrightarrow{\pi_{m}^{(t+1)}}=\widehat{\pi_{m}^{(t)}}+\alpha\left(o_{m}^{(t)}\left(\vec{X}^{(t+1)}\right)-\vec{\pi}_{m}^{(t)}\right) \\
\vec{\mu}_{m}^{(t+1)}=\vec{\mu}_{m}^{(t)}+o_{m}^{(t)}\left(\vec{X}^{(t+1)}\right)\left(\alpha / \hat{\pi}_{m}^{(t)}\right) \vec{\delta}_{m} \\
{\widehat{\sigma^{2}}}_{m}^{(t+1)}={\widehat{\sigma^{2}}}_{m}^{(t)}+o_{m}^{(t)}\left(\vec{X}^{(t+1)}\right)\left(\alpha / \hat{\pi}_{m}^{(t)}\right)\left(\overrightarrow{\delta_{n}^{T}}{\overrightarrow{\delta_{m}}}^{\left(\alpha^{2}\right.}{ }_{m}^{(t)}\right)
\end{gathered}
$$

이 때, $\alpha$ 는 학습률 변수로서 상수 $1 / T(T$ 는 혼합 모델에 사용하는 화소 데이터 총 수)로 근사화 한다. $o_{m}^{(t)}$ 은 소속 (ownership) 변수로서 화소 값이 $\mathrm{m}$ 번째 가우시안 분포에 근접한 값을 갖는지 판단한다. 판단할 때, 마할라노비스 (Mahalanobis)의 거리를 이용하여 측정하고 가우시안 혼합 모델의 출력 값을 구분한다. 단, 배경과 전경을 분리해 낼
때에는 둘의 구분을 위하여 배경이 전경에 비해 혼합 가중 치가 높은 것과 적은 분산 값을 가지는 특징을 파악하여 처리해야 한다. 이러한 배경과 전경의 분리를 위해 사용되 는 배경 분포 모델은 식 (5)와 같다.

$$
\left.B=\arg _{b} \min _{b=1}^{b} \widehat{\pi_{m}}>\left(1-T_{f}\right)\right)
$$

$1-T_{f}$ 는 배경 모델에게 주어지는 가중치의 값을 의미 한다. 새로운 화소 값이 배경에 속하게 되려면 식 (6)에 의해 프레임이 경과하면 속하게 된다. 즉, 새로운 화소 값이 배경으로 포함될 때까지의 경과하는 프레임을 의미 한다.

$$
F=\log \left(1-T_{f}\right) / \log (1-\alpha)
$$

\section{III. 제안한 방치되거나 제거된 객체 검출 알고리듬}

\section{1. 제안한 알고리듬의 소개}

본 논문에서는 앞에서 소개한 가우시안 혼합 모델을 기 반으로 한 추적 방식을 사용하여 방치 및 제거된 객체 검출 시스템을 설계 및 구현하였다. 그림 1은 본 논문에서 제안 한 알고리듬의 블록 다이어그램을 나타내고 있다. 최초 입 력된 영상에 대해 가우시안 혼합 모델에 의해 전경과 배경 을 분리하고 그림자제거에 강인한 그림자 제거 알고리듬을 적용한다. 그 후 모폴로지를 수행하여 주변 잡음을 제거하 고 객체를 구분을 명확히 하였다. 모폴로지가 수행된 블롭 (blob)에 레이블링(labeling)을 수행하여 각 블롭의 특징 정 보를 추출한다. 추출된 특징정보는 매 화면마다 블롭 정합 (matching) 방법을 적용하고, 결과로서 정지된 객체와 이동 중인 객체를 분리해 낸다. 정지된 객체는 버려지거나 제거 된 객체로 분리되어 다시 한 번 방치된 객체인지 제거된 객체인지 구분하여 이벤트 성격을 결정한다. 


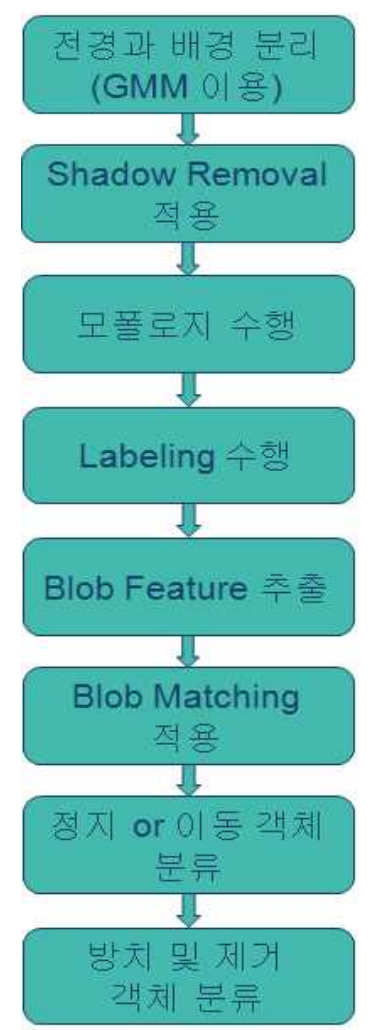

그림 1. 제안한 알고리듬의 블록 다이어그램

Fig. 1. Block Diagram of Proposed Algorithm

\section{2. 그림자 제거}

객체를 검출하는 과정에서 그림자는 객체의 형태를 왜곡 시킬 수가 있다. 추적하고자 하는 객체를 정확히 결정하기 위해서는 그림자의 제거가 필요하다. 그림자의 유형에는 크게 자기그림자(self shadow)와 주변그림자(cast shadow) 2 가지가 존재한다. 자기그림자는 객체 자체의 존재로부터 생성되는 그림자를 의미하고 주변그림자는 주변 환경적인 영향에 의해 생성되는 그림자를 의미한다. 두 가지 경우의 그림자를 적절하게 제거하기 위한 알고리듬은 밝기 왜곡 정보와 컬러 왜곡 정보를 이용한다 ${ }^{[13]}$.

$$
\begin{gathered}
B D=\operatorname{argmin}\left(\vec{F}_{\text {ore }}-\alpha \vec{B} a c k\right)^{2} \text { 또는 } \\
B D=\vec{F} \text { ore } \cdot \vec{B} a c k / \vec{B} a c k{ }^{2} \\
C D=\| \vec{F} \text { ore }-\alpha \vec{B} \text { ack } \|
\end{gathered}
$$

식 (7)을 이용하여 왜곡률을 계산한 후 임계값과의 관계를 이용하여 그림자를 제거 할 수 있다. 밝기 왜곡이 1.0 이상이 면 전경은 더 밝아지고 밝기 왜곡이 1.0 이하이면 전경은 어 두워진다. 임계값 1.0 은 실험적인 결과에 의해 얻었다.

본 논문에서는 식 (7)에서 컬러 왜곡 값의 계산량을 최소 로 줄이기 위해 그레이 영상에 적용하였다. 그림 2 는 그림자 제거를 수행하기 전과 수행한 후의 결과를 나타낸 것이다.

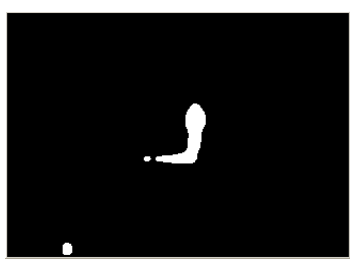

(a)

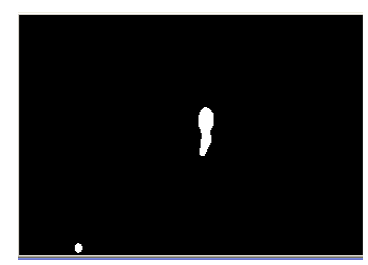

(b)
그림 2. 그림자 제거 방법을 적용한 결과 : (a)적용 전, (b)적용 후 Fig. 2 A Result of Shadow removal : (a) before shadow removal, (b)after shadow removal

\section{3. 블롭 정합}

객체의 이동경로를 파악하고 이전 화면과 현재 화면에서 같은 블롭인지 확인하기 위해서는 반드시 블롭 정합이 필 요하다. 블롭 정합은 두 블롭간의 유사도를 측정하게 되는 데 일정 임계치 이상이면 동일한 블롭으로 간주하고 그렇 지 않으면 동일하지 않은 것으로 간주한다. 이때 유사도를 측정하기 위해서 몇가지 파라미터가 요구된다. 첫 번째로 식 (8)과 같이 $c\left(a_{t}^{l}\right)$ 를 구한다.

$$
c\left(a_{t}^{l}\right)=\frac{1}{A\left(a_{t}^{l}\right)} \sum_{i=0}^{A\left(a_{i}^{l}\right)-1} P_{i}
$$

여기에서 $c\left(a_{t}^{l}\right)$ 은 블롭의 무게중심을 의미하고, $A\left(a_{t}^{l}\right)$ 는 블롭에 대한 픽셀을 모두 더한 면적을 의미하며, $P_{i}$ 는 블롭 의 픽셀의 위치를 의미한다.

그 다음으로는 식(9)와 같이 블롭 $\mathrm{a}$ 와 $\mathrm{b}$ 의 사이즈의 관계 에 대한 파라미터 $S$ 를 구한다.

$$
S\left(a_{t}^{l}, b_{t-\Delta t}^{l}\right)=\left|\frac{A\left(a_{t}^{l}\right)-A\left(b_{t-\Delta t}^{l}\right)}{A\left(a_{t}^{l}\right)+A\left(b_{t-\Delta t}^{l}\right)}\right|
$$


$D_{m}$ 값은 각 블롭의 폭과 높이의 평균값으로 정의된다.

$$
D_{m}=\frac{w i d t h(l)+h e i g h t(l)}{2}
$$

앞에서 구한 $(8),(9),(10)$ 의 식들을 이용하여 식 (11)과 같이 $k$ 값을 도출할 수 있다. 이렇게 도출된 $k$ 값은 두 개의 블롭이 동일한 것인지 판단하는 유사도로 사용된다.

$$
K\left(a_{t}^{l}, b_{t-\Delta t}^{l}\right)=1-\frac{D\left(a_{t}^{l}, b_{t-\Delta t}^{l}\right)}{D_{m}} S\left(a_{t}^{l}, b_{t-\Delta t}^{l}\right)
$$

논문의 실험에서는 0.6 의 임계치를 적용하였다. 위의 블롭 정합 알고리듬을 이용하여 매 화면간의 동일 블롭을 매칭하면서 추적하고자 하는 객체의 이동경로를 따라가 게 된다.

\section{4. 방치 및 제거 객체 분류}

변화를 나타내는 검출된 블롭이 방치된 객체인지 제거된 객체인지를 구별해내야 한다. Miguel ${ }^{[8]}$ 은 검출된 객체 위치 에서 배경화면 영역의 동일 위치와 입력된 현재 화면 영역 의 동일 위치에서의 히스토그램을 구하여 구별하는 방법을 제안하였다. 그러나 배경화면이 객체와 비슷한 색상을 가
지고 있을 경우에는 판별의 어려운 단점도 가지고 있다. 그 래서 본 논문에서는 영역성장(Region Growing) 기법을 이 용하여 방치된 객체와 제거된 객체를 분류하는 방법을 제 안하였다. 영역성장 기법은 특징이 같은 영역을 조금씩 성 장시켜 최종적으로는 영상 전체의 영역을 분할하는 방법으 로 소영역의 단위로 픽셀을 이용하는 경우는 픽셀 통합법 이라고도 불린다. 이 기법의 가장 큰 유의 사항은 처음 성장 시킬 초기점(seed point)을 찾는 방법인데 이 지점을 잘 결 정해야 좋은 성능을 기대할 수 있다. 그리하여 본 논문에서 는 객체에 해당하는 데이터의 히스토그램을 구하고 가장 큰 히스토그램 값을 갖는 좌표들을 초기점으로 선정하는 방법을 이용하였다. 그 결과 기존의 방법보다 더 잘 분류하 는 성능을 확인할 수 있었다.

\section{IV. 실험 및 결과 분석}

제안한 알고리듬을 바탕으로 본 장에서는 실험을 진행하 고 실험 결과에 대해서 분석을 하였다. 실험 환경은 Intel Core2 CPU의 Q6320 1.86GHz, 2GB RAM의 PC 환경에서 $\mathrm{OPENCV}$ 를 이용하여 구현하였다.

그림 3 은 지하철내에서 물건이 방치되는 상황을 직접 촬 영하여 실험한 결과이다. 그림 $3(\mathrm{a})$ 는 지하철 환경의 배경

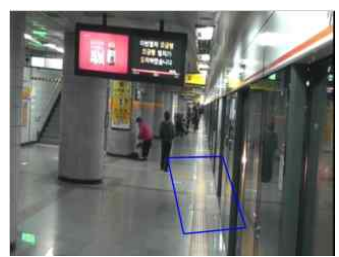

(a)

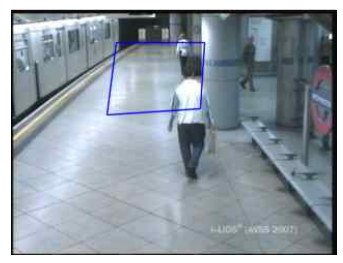

(e)

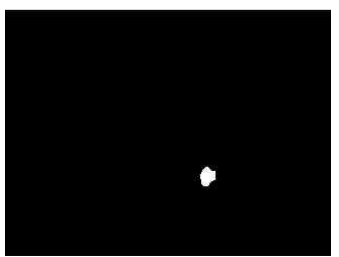

(b)

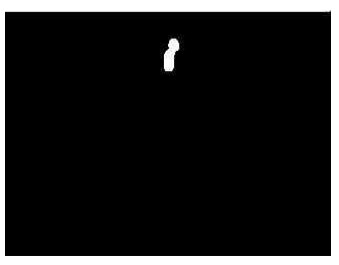

(f)

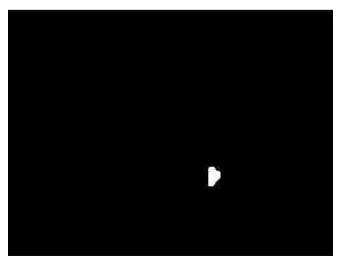

(C)

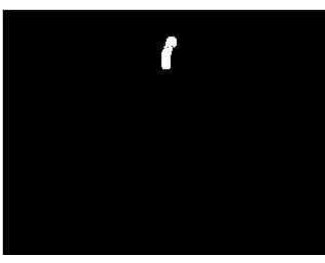

(g)

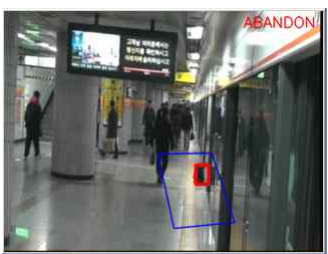

(d)

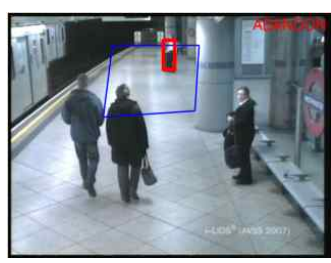

(h)

그림 3. 방치된 객체 검출의 실험결과 : (a)배경영상, (b)전경영상, (c)그림자제거영상, (d)결과영상, (e)배경영상, (f)전경영상, $(\mathrm{g})$ 그림자제거영상, (h)결과영상 Fig. 3. A Result of Abandoned Object Detection : (a)Background Image, (b)Foreground Image, (c)After Shadow Removal Image, (d)Result Image, (e)Background Image, (f)Foreground Image, (g)After Shadow Removal Image, (h)Result Image 
영상이고 그림 3(b)는 설정된 영역내에서 객체가 검출된 영 상이다. 그림 3(c)는 검출된 객체에 대해서 그림자제거 알 고리듬을 적용하여 그림자를 제거한 영상이다. 그림 3(c)에 서 보는 것과 같이 좌측의 그림자가 조금 제거된 결과를 얻을 수 있었다. 앞의 과정을 토대로 승강장의 스크린 도어 앞에서 객체가 방치된 후 일정 시간이 경과되면 방치된 객 체가 검출된다. 여기에서 경과시간 뿐만 아니라 방치된 객 체의 크기도 설정할 수 있다. 그림에서 보이는 파란 사각형 인 ROI(관심영역)도 원하는 위치에서 설정할 수 있다. 그림 $3(\mathrm{~d})$ 는 ROI영역 내에서 방치된 객체가 정확하게 검출된 것 을 보여준다. 둘째 줄의 그림은 AVSS 2007(Advanced Video and Signal-based Surveillance) 동영상을 가지고 실 험한 결과이다. 여기에서 AVSS2007 실험 동영상은 i-LIDS (Image Library for Intelligent Detection System)의 데이터 셋과 동일하며, i-LIDS는 영국의 Home Office 사에서 만든 $\mathrm{VA}($ Video Analytics) 시스템 실험용 라이브러리로서 지능 형 영상분석을 위해 대표적으로 사용하는 영상들이다. 그 림 3(e)는 배경영상이고 그림 3(f)는 설정된 영역 내에서 방 치된 객체가 검출된 영상이다. 어떤 사람이 가방을 방치하 고 있는 상황이 검출 되었고, 객체와 함께 사람 신체의 일부 분도 같이 검출되는 것을 확인할 수 있었다. 그림 $3(\mathrm{~g})$ 는 앞서 검출된 영상에서 그림자 제거를 적용한 영상이다. 검
출된 객체는 그림자를 갖고 있지 않아 그림 3(f)와 동일한 영상을 획득하였다. 그림 $3(\mathrm{~g})$ 는 방치된 객체가 검출되는 결과를 표시한 영상이다. 그림에서 보이는 것과 같이 일정 시간이 경과된 후 설정된 영역 내에서 방치된 객체가 검출 되는 결과를 얻을 수 있었다. 앞의 두 번의 실험 결과에서 보는 것과 같이 지하철 역사 내에서 사람의 이동에 의한 객체의 폐색현상에도 불구하고 방치된 객체가 잘 검출되는 것을 확인할 수 있었다.

그림 4는 제거된 객체가 검출되는 실험결과를 보여준다. 그림 4(a)는 배경영상이고 그림 4(b)는 그림자가 제거되기 전의 검출된 객체에 대한 이진영상이며, 그림4(c)는 그림자 가 제거된 후의 영상이다. 그림에서 보는 것과 같이 하단부 의 그림자가 많이 제거된 것을 확인할 수 있다. 그림 4(d)는 $\mathrm{ROI}$ 영역 내에 있던 객체가 일정시간 경과 후 제거된 객체 가 검출된 결과 영상이다. 또한, 그림 4(e)는 배경영상 이고, 그림 4(f)는 액자가 사라진 후 검출된 객체의 영상이다. 그 림 $4(\mathrm{~g})$ 는 앞서 검출된 전경영상을 그림자 제거 처리한 후 의 영상이며, 그림 $4(\mathrm{~g})$ 는 제거된 객체의 그림자 제거 결과 영상이다. 그림 $4(\mathrm{~h})$ 는 벽에 걸려있던 액자가 제거되면 알 람과 함께 제거된 객체의 위치를 표시해주는 것으로 정확 하게 제거된 객체가 검출되는 실험결과를 보여준다.

앞에서 설명한 $\mathrm{PC}$ 기반의 프로그램 성능 테스트와 더불

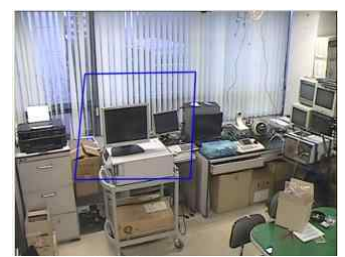

(a)

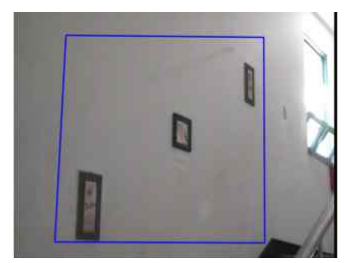

(e)

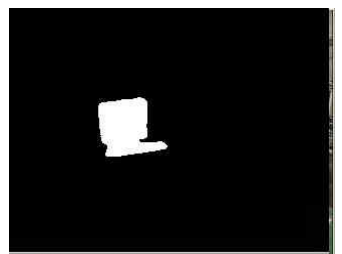

(b)

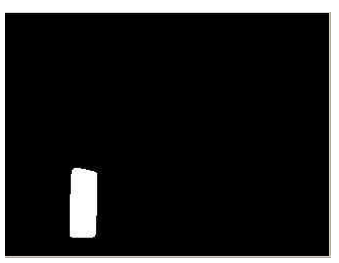

(f)

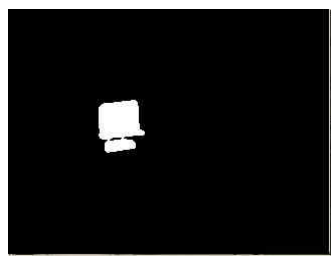

(C)

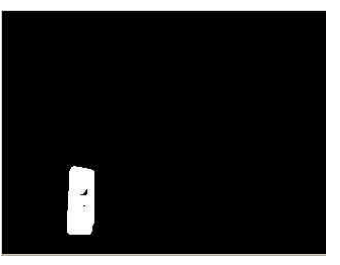

(g)

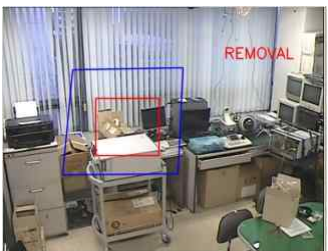

(d)

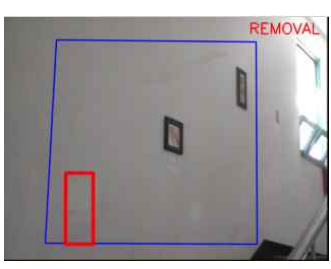

(h)

그림 4. 제거된 객체 검출의 실험결과 : (a)배경영상, (b)전경영상, (c)그림자제거영상, (d)결과영상, $(\mathrm{e})$ 배경영상, (f)전경영상, $(\mathrm{g})$ 그림자제거영상, $(\mathrm{h})$ 결과영상 Fig. 4. A Result of Removed Object Detection: (a)Background Image, (b)Foreground Image, (c)After Shadow Removal Image, (d)Result Image, (e)Background Image, (f)Foreground Image, (g)After Shadow Removal Image, (h)Result Image 
어 DSP 기반으로도 테스트를 수행하였다. 실험 장비로는 PTZ카메라인 Hitron사의 FASTRAX3 36x NTSC, Monitor HHM190BN, Keyboard HKBD01, STANDALONE Board 를 사용했고, JTAG XDS510USB, Code Composer Studio 3.3 을 사용하였으며, 관련 라이브러리로는 TI사의 IMAGE LIBRARY, VISION LIBRARY, IQMATH LIBRARY를 사용하였다. 단독장치(standalone) 형태의 제안한 시스템은 그림 5 와 같다.

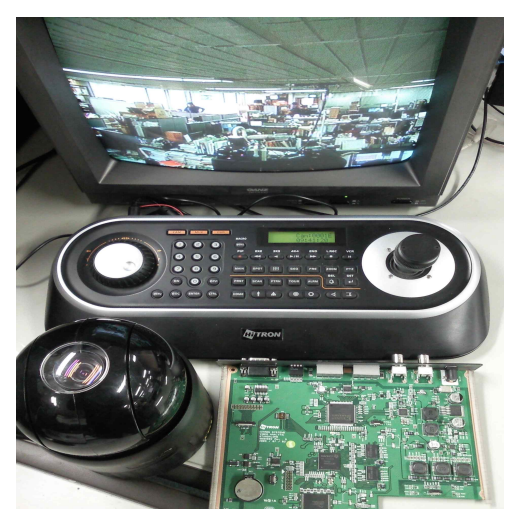

그림 5. DSP 기반의 실험 환경

Fig. 5 Test Environment of DSP-based Implementation

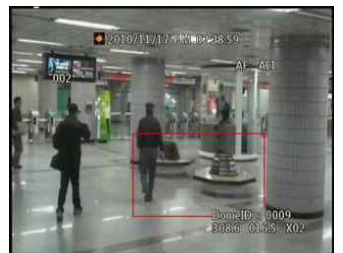

(a)

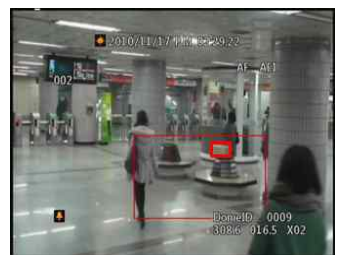

(b)

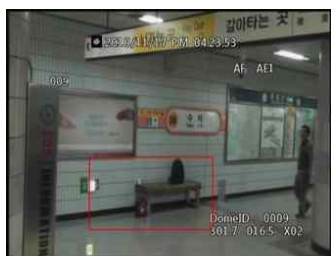

(c)

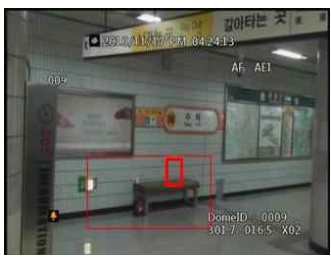

(d)

그림 6. DSP 기반의 방치 및 제거된 객체 검출의 실험결과 (a)방치이벤트 배경영상, (b)방치이벤트 현재영상, (c)제거이벤트 배경영상, (d)제거이벤트 현재영상 Fig.6 A Result of DSP-based of Abandoned and Removal Object Detection (a) Background Image of Abandon Event, (b) Current Image of Abandon Event (c) Background Image of Removal Event, (d) Current Image of Removal Event

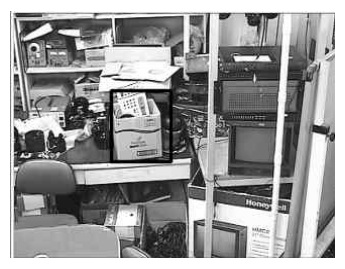

(a)

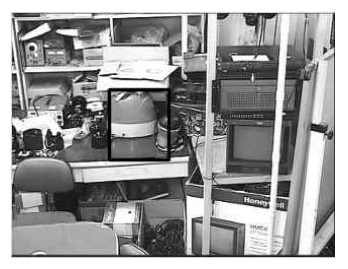

(b)

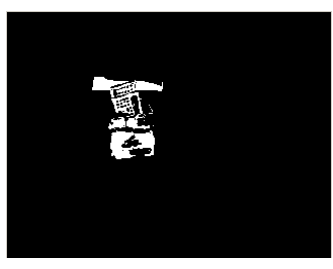

(c)

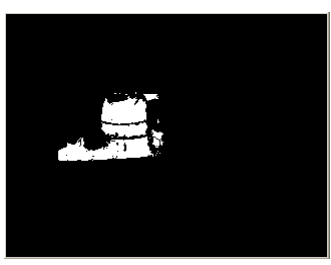

(d)

그림 7. 영역 성장법을 이용한 제거된 객체 검출결과 : (a)배경영상, (b)현재영상, (c)배경영상(영역성장 후) (d)현재영상(영역성장 후)

Fig. 7. A Result of Removed Object Detection by Region Growing Method (a)Background Image, (b)Current Image, (c)Background Image(after Region Growing method) (d)Current Image(after Region Growing method) 
적용한 이진 영상이고, 그림 7(d)는 현재영상에 대해서 객 체의 위치에서 영역 성장법을 적용한 이진 영상이다. 영역 성장법을 이용하여 방치된 객체와 제거된 객체를 분류하는 기준은 그림 (c)와 (d)를 획득한 다음 성장된 영역을 비교하 여 배경영상이 더 많이 영역 성장이 되면 방치된 객체로 분류하고 현재영상이 더 많이 영역 성장이 되면 제거된 객 체로 분류하게 된다. 지속적인 실험결과 영역 성장법이 항 상 잘 분류 하는 것은 아니지만 히스토그램을 이용할 때 보다는 확률적으로 높은 성공률을 보였다.

표 1. 방치되거나 제거된 객체 검출 알고리듬의 검출 성능 측정 Table 1. Performance of the detection algorithm for abandoned and removed objects

\begin{tabular}{|c|c|c|}
\hline & $\begin{array}{c}\text { 방치된 객체 검출 } \\
(23 \text { 회 })\end{array}$ & $\begin{array}{c}\text { 제거된 객체 검출 } \\
(19 \text { 회 })\end{array}$ \\
\hline 검출 성공 횟수 & 19 회 검출 & 16 회 검출 \\
\hline 검출율 & $19 / 23=82.6 \%$ & $16 / 19=84.2 \%$ \\
\hline
\end{tabular}

표 1 은 방치되거나 제거된 객체 검출 알고리듬의 검출 성 능을 나타낸 표이다. 실험은 실내에서 수행되었고, 영상은 전경, 배경, 현재 영상만을 추출하여 실험하였다. 일반적인 환경에서 방치된 객체 검출은 23 회, 제거된 객체 검출은 19 회를 수행하였다. 그 결과 표 1 과 같이 방치된 객체 검출률 은 $82.6 \%$, 제거된 객체 검출률은 $84.2 \%$ 의 성능을 보였다.

표 2. 분류 알고리듬의 성능 비교

Table 2. Performance comparison among classification methods

\begin{tabular}{|c|c|c|c|c|}
\hline 성능 방법 & Histogram & 영역비교 & $\begin{array}{c}\text { 영역성장법 } \\
\text { (초기점:평균값) }\end{array}$ & $\begin{array}{c}\text { 영역성장법 } \\
\text { (초기점:Histogram) }\end{array}$ \\
\hline 성공 횟수 & $\begin{array}{l}\text { 42회중 } \\
\text { 32회 }\end{array}$ & $\begin{array}{l}\text { 42회중 } \\
\text { 29회 }\end{array}$ & $\begin{array}{l}\text { 42회중 } \\
\text { 33회 }\end{array}$ & $\begin{array}{l}\text { 42회중 } \\
\text { 35회 }\end{array}$ \\
\hline 검출율 & $76.2 \%$ & $69 \%$ & $78.5 \%$ & $83.3 \%$ \\
\hline
\end{tabular}

표 2는 방치된 객체와 제거된 객체를 분류하는 알고리듬 들의 성능비교 표이다. 실험은 실내에서 수행되었고, 영상 은 전경, 배경, 현재 영상만을 추출하여 동일한 영상을 입력 으로 설정하여 실험하였다. 히스토그램은 Miguel[8]이 제 안한 분류 알고리듬을 구현한 것이고, 영역비교 방법은 배
경 영상과 현재 영상에서 객체의 영역을 각각 누적하여, 누 적된 영역을 비교하는 방법을 구현한 것이다. 영역성장법 은 초기점을 어떻게 결정하느냐에 따라서 성능이 크게 좌 우된다. 그래서 본 논문에서는 영역성장법을 적용할 때 초 기점을 평균값과 히스토그램 두 가지를 적용해 보았다. 그 결과 히스토그램을 적용한 영역 성장법이 $83.3 \%$ 로 가장 높 은 성능을 나타냈다.

\section{V. 결 론}

본 논문에서는 $\mathrm{GMM}$ 을 기반으로 전경과 배경을 분리하 고 추적을 통하여 방치되거나 제거된 객체를 검출하는 시스 템을 제안하였다. 또한, 객체 검출 전 그림자를 제거하여 정 확한 객체를 검출하고자 하였고, 기존의 방치된 객체와 제거 된 객체를 잘못 분류하는 오경보율을 줄이고자 영역성장법 을 이용한 방치 및 제거된 객체를 분류하는 방법도 제안하였 다. 4장의 실험결과에서 볼 수 있듯이 복잡한 환경에서도 강 인하게 객체를 정확하게 검출함과 동시에 방치 및 제거된 객체를 정확하게 분류하는 것을 확인할 수 있었다. 향후 연 구 계획으로는 더욱 복잡한 환경에서도 검출 성능을 유지하 며 동시에 지속적인 폐색에 대한 문제점을 분석하여 더욱 강건한 성능을 갖는 방법에 대해서 연구를 진행할 계획이다.

\section{참 고 문 헌}

[1] Sadiye. Guler and M. K. Farrow, :"Abandoned Object Detection in Crowded Places", IEEE International Workshop on PETS, pp.99-106, 2006.

[2] Chih-Yang Lin and Wen-Hao Wang, "An Abandoned Objects Management System Based on the Gaussian Mixture Model", IEEE Computer Society, International Conference on Convergence and Hybrid Information Technology, pp.169-175, 2008.

[3] Ying-li Tian, Rogerio Feris and Arun Hampapur, "Real-Time Detection of Abandoned and Removed Objects in Complex Environments", in The Eighth International Workshop on Visual Surveillance - VS2008, Marseille : France, 2008.

[4] P. L. Venetianer, Z. Zhang, W. Yin and A. J. Lipton, "Stationary Target Detection using The Objectvideo Surveillance System", Advanced Video and Signal Based Surveillance(AVSS), pp.242-247, 2007.

[5] Álvaro Bayona, Juan Carlos San Miguel and José M. Martínez, 
"Comparative evaluation of stationary foreground object detection algorithms based on background subtraction techniques", Advanced Video and Signal Based Surveillance(AVSS), pp25-30, 2009.

[6] Liao,H-H., Chang,J-Y. and Chen, L-G. "A localized Approach to abandoned luggage detection with Foreground-Mask sampling", Proc. of AVSS 2008, pp. 132-139,2008.

[7] Porikli, F., Ivanov, Y. and Haga, T. "Robust Abandoned Object Detection Using Dual Foregrounds", Journal on Advances in Signal
Processing, volume2008, Jan., 2008.

[8] Juan Carlos San Miguel, José M. Martínez, "Robust unattended and stolen object detection by fusing simple algorithms", Advanced Video and Signal Based Surveillance, pp.18-25, 2008.

[9] 전지혜, 박종화, 정철준, 강인구, 안태기, 박구만, “실시간 지능형 감시 시 스템을 위한 방치, 제거된 객체 검출에 관한 연구”, 2010년 한국통신학회 논문지, 제 35권 1호, pp.24-32, 2010.

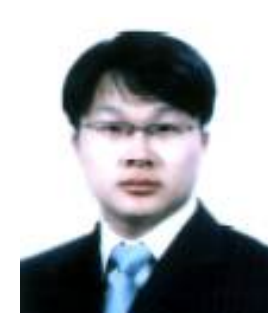

\section{정 철 준}

- 2006년 2월 : 수원대학교 전자공학과 학사

- 2008년 2월 : 수원대학교 전자공학과 석사

- 2008년 3월 현재 : (주)하이트론씨스템즈 주임연구원

- 주관심분야 : 영상처리, 지능형 알고리즘, 물체 추적

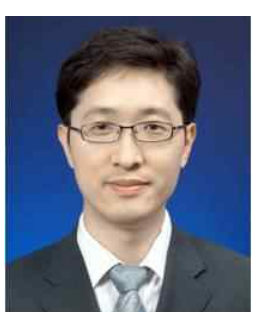

안 태 기

- 1993년 2월 : 경북대학교 전자공학과 학사

- 1996년 2월 : 경북대학교전자공학과 석사

- 2011년 2월 : 성균관대학교 전자전기컴퓨터공학과 박사

- 1996년 3월 2010년 6월 : 한국철도기술연구원 선임연구원

- 2010년 6월 현재 : 한국철도기술연구원 책임연구원

- 주관심분야 : 멀티미디어 통신, 영상분석, 인공지능

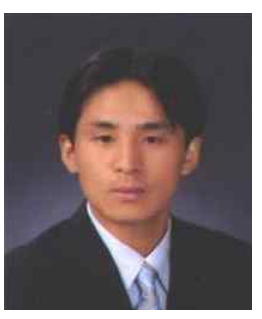

\section{박 종 화}

- 2002년 2월 : 홍익대학교 전기전자정보통신 공학부

- 2005년 2월 : 홍익대학교 전자공학과 석사

- 2005년 1월 2007년 10월 : IDTECK

- 2007년 11월 현재 : (주)하이트론씨스템즈 선임연구원

- 주관심분야 : 영상처리, DSP

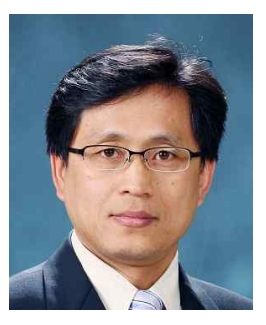

\section{박 구 만}

- 1984년 2월 : 한국항공대학교 전자공학과 학사

- 1986년 2월 : 연세대학교대학원 전자공학과 석사

- 1991년 2월 : 연세대학교대학원 전자공학과 박사

- 1991년 3월 1996년 9월 : 삼성전자 신호처리연구소 선임연구원

- 1996년 9월 1999년 7월 : 호남대학교 전자공학과 조교수

- 2006년 1월 2007년 8월 : Georgia Institute of Technology Dept. of Electrical and Computer Engineering, 방문교수

- 1999년 8월 현재 : 서울과학기술대학교 매체공학과 교수

- 주관심분야 : 멀티미디어 통신, 영상신호처리 및 컴퓨터비전 